\title{
Bibliografia Comentada em Educação a Distância e Práticas Educativas Comunicacionais e Interculturais
}

\author{
Organizada por Luís Paulo Leopoldo Mercado \\ Universidade Federal de Alagoas
}

ALVES, Lynn; MOREIRA, José A. (otgs). Tecnologias \& aprendizagem: delienando novos espaços de interação. Salvador: Edufba, 2017.

O livro aborda as tecnologias digitais em distintos cenários de aprendizagem, a exemplo dos espaços hospitalares e prisionais. Discute novas trilhas nas investigações que têm as tecnologias como elementos mediadores de questões cognitivas, afetivas, educacionais, culturais e sociais. Explora possibilidades que emergem com a mediação de tecnologias digitais que rompem os limites territoriais e a concepção de que se aprende apenas no ambiente escolar. Analisa a mediação de tecnologias digitais em MOOC e outras interfaces da web, dando voz a esses sujeitos para que possam verbalizar os sentidos e significados que estabelecem para essa mediação e aprenderem fora do universo escolar. Capítulos: Repensar políticas e pedagogias para uma educação superior apetecível!; MOOC - evolução ou revolução da aprendizagem?; O eLearning para à inclusão digital de reclusas de um estabelecimento prisional português; Educação a distância e elearning no ensino superior em estabelecimentos prisionais: projeto de desenvolvimento em Portugal; A televisão como meio educativo na prisão: reflexões sobre a audiência de programas policiais no cárcere; Tecnologias digitais e da web no contexto hospitalar: possíveis ressignificações de práticas educacionais; Composição de redes entre pedagogia, saúde mental e tecnologias digitais; Programas de intervenção mediados por computador: potencialidades para reabilitação em redes no ambiente escolar; Brincadeiras espontâneas e tecnologias digitais: notas para reflexão sobre a aprendizagem sociocultural em contextos extraescolares contemporâneos; (multi) letramentos e formação de professores na sociedade digital: entretecento (desa)fios.

ANTOUN, Henrique (org). Web 2.0: participação e vigilância na era da comunicação distribuída. Rio de Janeiro: Mauad X, 2008.

O livro aborda as transformações impulsionadas pela radicalização da participação na rede propiciada pela nova fase da web. Discute as novas configurações trazidas pela participação na rede para a comunidade, o território e o jogo. Discute a geração do comum e o novo lugar do capital social e o problema da nova face da vigilância, através do monitoramento dos dados produzidos pela participação. Analisa a compreensão da violência transpolítica, construindo o conceito de visibilidade midiática para avaliar sua repercussão social e histórica como parte do fenômeno glocal. Capítulos: As transformações da participação na sociedade hiperconectada; Perspectiva histórica - de uma teia à outra: a explosão da comum e o surgimento da vigilância participativa. Parte 1 - Novas Configurações da participação: comunidade, território e jogo - Por um novo conceito de comunidade: redes sociais, comunidades pessoais, inteligência coletiva; Comunicação e práticas sociais no espaço urbano: as características dos dispositivos móveis de conexão multirrede (DHMCM); G.A.M.E.S.2.0 - Gêneros e gramática de arranjos e ambientes midiáticos moduladores de experiências de entretenimento, sociabilidades e sensorialidades. Parte 2 - Produção Participativa: capital social e geração do comum - Modelos de colaboração 
nos meios sociais da internet: uma análise a partir dos portais de jornalismo participativo; O aspecto relacional das interações na web 2.0; Práticas de sociabilidade em sites de redes sociais: interações e capital social nos comentários do fotolog.com; O seu buscador Ihe satisfaz? A folksonomia como alternativa de representação e recuperação de informação na web 2.0. Parte 3 - Participação e monitoramento: a nova face da vigilância; Monitoramento, classificação controle nos dispositivos de vigilância digital; Quem procura acha? O impacto dos buscadores sobre o modelo distributivo da world wide web. Parte 4 - Participação e Violência Transpolítica - visibilidade mediática e violência transpolítica na cibercultura: condição atual da repercussão social-histórica do fenômeno glocal. Parte 5 - A Paixão Participativa: visibilidade e memória Crônicas da boneca desejada: fantasias da vida real; Em busca da aura perdida: espetacularizar a intimidade para ser alguém; Cérebro, corpo e subjetividade na tecnocultura contemporânea.

\section{AZEVEDO, Adriana B.; PASSEGGI, Maria C. (orgs) Narrativas das experiências docentes} com o uso de tecnologias na educação. São Bernardo do Campo: Universidade Metodista de São Paulo, 2015.

O livro aborda a temática do uso de tecnologias no campo da educação, focalizando de modo especial a educação básica. Apresenta narrativas produzidas por docentes sobre o uso de meios digitais em suas práticas pedagógicas. Analisa experiências diversificadas no uso de TDIC, permitindo que sejam visualizadas novas formas assumidas na prática pedagógica com a utilização dos mesmos. Discute os processos de ensino e aprendizagem e as formas de interação e comunicação entre alunos e docentes, evidenciando que o uso de TDIC parece estimular mais os alunos, pautado no diálogo entre os mesmos e os docentes. Ao narrar suas experiências, são apontadas as dificuldades, assim como as estratégias desenvolvidas pelos educadores e alunos para superá-las. Capítulos: Narrativas das experiências: O uso de meios digitais para a troca de experiências bem sucedidas entre professores da educação básica; Ações tecnológicas para o Saresp: a prática do uso de simulados online; Projeto TV Cedro Rosa: a Grande São Paulo vista pelos olhares dos pequenos; Da prática à escrita: experiências mediadas pelo uso das tecnologias digitais na educação; O uso de jogos nas aulas de filosofia: o lúdico tecnológico; Fazer diferente é fazer a diferença: o uso de tecnologias digitais como proposta educativa; Narrativas de usos pedagógicos de ferramentas tecnológicas na docência do Ensino Médio; O coordenador pedagógico como formador e incentivador de práticas com uso das TDIC; Educação e tecnologia: pontos de uma mesma reta; Sala de Aula ampliada: além dos limites espaçotemporais escolares; Crescendo e jogando: games em educação.

BERGER, Robert N. Ética na computação: uma abordagem baseada em casos. Rio de Janeiro: LTC, 2011.

O livro aborda a questão da responsabilidade de um sistema ou programa de computação suspeito de facilitar fraudes, destruir a reputação das pessoas, arruinar empresas. Analisa de quem é a culpa: da máquina ou do homem que a constrói e opera. Apresenta um guia para ajudar a resolver dilemas éticos na área da computação, partindo de princípios filosóficos. Capítulos: Introdução; O computador como um agende humanitário; Sistemas de crença filosófica; Um inventário filosófico; A possibilidade de uma Teoria Ética unificadora; O processo de tomada de decisão ética; Psicologia e ética na computação; O campo da computação como uma profissão; Códigos de Ética relacionados à computação; Ética na computação e desenvolvimento internacional; Robótica e ética; Questões de roubo e pirataria; Casos referentes à privacidade; Casos referentes à privacidade; Questões de poder; Casos referentes ao poder; Uma coleção variada de casos; O caso da computação parasita. 
BRYNJOLFSSON, Erik; McAFEE, Andrew. A segunda era das máquinas: trabalho, progresso e prosperidade em uma nova época de tecnologias brilhantes. Rio de Janeiro: Alta Books, 2015.

O livro aborda as forças que promovem a reinvenção das vidas das pessoas e da economia. Analisa o impacto das tecnologias digitais e a riqueza das tecnologias pessoais, infraestrutura avançada e acesso a quase sem fronteiras aos itens culturais que enriquecem a vida dos indivíduos. Discute o progresso tecnológico, social e econômico frente as tecnologias e a necessidade de modificações na educação e desenvolver novas colaborações, para preparar para a nova Economia. Capítulos: As granes histórias; As habilidades das novas máquinas: a tecnologia sai na frete: A Lei de Moore e a segunda metade do tabuleiro do xadrez; A digitalização de quase tudo; Inovação: declínio ou recombinação? Inteligência artificial e humana na segunda Era das Máquinas; Recompensa da computação; Além do PIB; A dispersão; Os maiores vencedores: estrelas e superestrelas; Implicações da riqueza e da dispersão; Aprendemos a correr com as máquinas: recomendações para indivíduos; Recomendações de política; Recomendações de longo prazo; Tecnologia e futuro.

\section{CARNEIRO, Tereza K.; RIOS, Jocelma A.; SOUZA, Cláudio R. (orgs). Tecnologias aplicadas a} Saúde. Salvador: Edufba, 2016.

O livro aborda estudos e pesquisas acerca das tecnologias aplicadas à Saúde, envolvendo a utilização de recursos médicos em plataformas digitais, tecnologias assistivas, Teoria das Redes Sociais e Complexas, contribuições das tecnologias na medicina dentirária, proposta de modelo computacional capaz de aprender comportamentos rotineiros de idoso. Apresenta técnica de estudo baseada em redes neurais para diagnóstico automático de retinopatia diabética e tecnologias que envolvem a radiologia digital. Capítulos: Equipamentos médicos de baixo custo com Arduíno; Equipamentos, sinais e sensores mioelétricos; Tecnologia assistiva para acessibilidade: protótipo de bengala automatizada para detecção de obstáculos; Avaliação da tecnologia aplicada à Saúde em sistemas de ar medicinal e vácuo; Teoria das Redes para estudos na área de Saúde; Difusão do conhecimento; Tecnologia e Formação: Teoria de Redes e aplicações; Decomposição de sinais para detecção de epilepsia; Estudo comparativo de métodos de segmentação em imagem de raio-X panorâmicos dos dentes: monitoramento remoto e não-intrusivo de idosos; Uso de Aprendizagem Profunda em detecção automática de retinopatia diabética; Radiologia digital: características técnicas e aspevtos de controle de qualidade na legislação nacional.

DUDENEY, Gavin; HOCKLY, Nick; PEGRUM, Mark. Letramentos digitais. São Paulo: Parábola, 2016.

O livro aborda o impacto das novas tecnologias na aprendizagem linguística que exige a aquisição de novas habilidades e estratégias pelos educadores e estudantes para poderem ter acesso ao potencial que essas ferramentas podem oferecer. Apresenta uma taxonomia dos letramentos digitais que os estudantes e educadores necessitam para ter acesso as possibilidades educacionais que as novas tecnologias oferecem. Discute quatro tipos de letramentos: letramentos relacionados à linguagem e comunicação do sentido (letramento impresso, letramento multimídia e o letramento móvel); os letramentos relacionados à informação (letramento em pesquisa, letramento em informação e o letramento em filtragem); Os letramentos relacionados às conexões (letramento em rede, letramento participativo e o letramento intercultural); e o letramento relacionado ao (re) desenho (letramento remix). Apresenta propostas de atividades para uso de tecnologias em sala de aula, envolvendo letramento digital e aprendizagem linguística interdisciplinar. Capítulos: Da pesquisa às implicações; Das implicações à aplicação; Da aplicação à implementação; Da implementação à pesquisa. 


\section{FUNDAÇÂO Telefônica Vivo. Experiências avaliativas de tecnologias digitais na educação. São Paulo: Fundação Telefônica Vivo, 2016}

O livro aborda as fronteiras entre educação e tecnologias, os dilemas e as oportunidades de avaliações realizadas em projetos que aliam educação e inovação. Discute como avaliar os métodos utilizados e os resultados da avaliação envolvendo programas que tratam de educação e tecnologias digitais. Capítulos: Avaliação do uso de tecnologias digitais na educação pública. Seção 1 - A avaliação de tecnologias digitais aplicadas à educação; Educação, tecnologia e avaliação: por um uso pedagógico efetivo da tecnologia em sala de aula; Os desafios da avaliação de programas de inovação educacional. Seção 2 - Experiências e casos de avaliação - Plano Ceibal: novas tecnologias, pedagogias, formas de ensinar, aprender e avaliar; Avaliar significa criar condições para ampliar a apropriação das tecnologias na educação; Rede Enlaces, Ministério da Educação do Chile. Seção 3 - Reflexões e perspectivas Reflexões em torno dos cenários educacionais de integração em TIC.

JARALITA, Beatriz; IMBERNÓN, Francisco. Pensando no futuro da educação: uma nova escola para o século XXII. Porto Alegre: Penso, 2015.

O livro aborda os dilemas e preocupações enfrentados no século XXII pelas sociedades, culturas e instituições. Discute o futuro das sociedades, o significado da escola como espaço-tempo da informação, da comunicação e do conhecimento, a formação e o desenvolvimento profissional de professores, os fatores que determinam o agrupamento de alunos na escola e alguns requisitos para realizar inovações neste âmbito, o ensino e aprendizagem de línguas estrangeiras partindo das realidades e necessidades linguísticas presentes na atualidade. Capítulos: Por que nos importamos com a educação do futuro? Um livro educativo ucrônico e utópico sobre o futuro; Escola e sociedade no século XXII; A escola contínua e o trabalho no espaço-tempo eletrônico; Os professores daqui a cem anos. Brincando com o tempo; Os alunos na escola do amanhã; Adiantar-se ao futuro: agrupamentos de alunos; Na escola, o futuro já não é o passado, ou é. Novos currículos, novos materiais; A construção escolar no século XXII; Aprender línguas estrangeiras nas aulas dos séculos XXI e XXII. O caminho para uma escola conectada, global e plurilíngua; Pensar na avaliação como recurso de aprendizagem.

LINHARES, Ronaldo; CARLA, Andreia; COSTA, Antonio P. (orgs). Pesquisa qualitativa em educação, comunicação e saúde: proposições, experiênciase resultados. Aracaju: Edunit, 2016.

O livro aborda estudos e resultados de pesquisas voltadas para proposições e experiências de docência, uso e gestão de TIC no espaço escolar e os resultados de estudos e pesquisas sobre as mídias e tecnologias digitais na aprendizagem. Capítulos: A mídia e a construção da lógica na escola: a não-linearidade na prática pedagógica; A repetência escolar: uma forma de exclusão da classe de repetentes? Um estudo de caso etnográfico; Educação na cibercultura: transmídia, fanfiction, "o meio e a mensagem"; Análisis del abandono educativo desde metodologias mixtas; Autismo: barras cuisenaire para que vos quero? Claves para la comunicación eficaz en el aula mediante su gestión com PNL; Classe hospitalar: o atendimento educacional no Hospital de Reabilitação e Readaptação Crer em Goiânia; Construção de documentários pedagógicos com enfoque Ciência-Tecnologia-Sociedade-Ambiente: uma investigação qualitativa na educação em Ciências; Gestão, competências e educação a distância: estudos nos polos de apoio presencial da Unit. 
MAUCHART, Susan. O inverno da nossa desconexão: como uma mãe e três adolescentes passaram seis meses totalmente desconectados e sobreviveram para contar a história. São Paulo: Paz e Terra, 2011.

OAborda a experiência de um adulto e três adolescentes numa casa totalmente desconectada de qualquer mídia durante seis meses, valorizando as qualidades mais humanas, como a da conexão com os que estão à sua volta, ao vivo, em cores. A experiência mostra que a tecnologia traz avanços insuperáveis no âmbito do trabalho, do estudo e do lazer, mas também pode tomar tempo indiscutivelmente precioso e manter os indivíduos isolados. Analisa pesquisas sobre mídia, aprendizagem e adolescência. Capítulos: Quem somos e porque apertamos o pause; Decisão enérgica: cai a escuridão; Tédio para iniciantes; meu iphone/Eu mesma: observações de uma fugitiva digital; O som da mão fazendo a lição de casa; A perda do Facebook: fazendo amigos à moda antiga; Comer, jogar, dormir; O retorno do nativo digital.

MORAES, Denise R. Mídias na formação de professores(as): limites e possibilidades. São Paulo: Paco Editorial, 2016.

O livro aborda o mapeamento do terreno brasileiro, por meio da análise de um programa de formação Mídias na Educação e, observação in loco de programas e políticas de orientação do uso das tecnologias nas escolas portuguesas expressa que a função como educador é contribuir para que as tecnologias e mídias no espaço da escola e da sala de aula sejam problematizadas e significadas pedagogicamente. Capítulos: Diálogos iniciais; Mapeando o terreno; O Programa Mídias na Educação: abordagem Inicial; Interface das pesquisas sobre mídias e educação: breve panorama; Percorrer e tecer o caminho - O Programa Mídias na Educação: possibilidades e limites; Formação de professores brasileiros para as mídias: novos caminhos ou caminhos novos?; Formação de professores para o uso das tecnologias: a experiência portuguesa.

PILLA, Branca S. E-learning corporativo: estrutura e avaliação. São Paulo: Paco Editorial, 2016.

O livro aborda o conceito de inclusão digital utilizado nas políticas públicas atuais compreendendo as TIC como parte da cultura digital. Discute o uso das TIC como ferramentas e suporte didático sem gerar mudanças estruturais no contexto escolar. Capítulos: Tecnologia, desenvolvimento e exclusão; Inclusão digital e educação; Tecnologias móveis na educação: uma pesquisa comparativa; Formação de professores e cultura digital.

PRYSTHON, Angela; CUNHA, Paulo. Ecos urbanos: a cidade e suas articulações midiáticas. Porto Alegre: Sulina, 2008.

O livro aborda a comunicação e as representações midiáticas da cidade e a ressignificação destas na cultura contemporânea. Discute os processos sociais e comunicacionais que legitimam ou marginalizam manifestações urbanas. Aborda questões referentes à urbanidade midiática, sublinhando a evolução histórica do conceito de cidades a partir de sua relação com os processos comunicacionais. Capítulos: Cinema e Cidades - A metrópole cindida: o clichê do melodrama no interior das narrativas documentárias; Entre clarões e trevas: a cidade noir no paracinema; A cidade nua: regimes de representação. Cidade como Mídia - As mulheres, os homens e o mêtro; Cidades palimpsestas, cidades midiáticas: limiaridades e errâncias que produzem significação; Vida na metrópole: comunicação visual e intervenções juvenis em São Paulo. Cidades e Tecnologias A cidade como rede tecnológica; Fluxos de notícias e cidades: redes digitais, urbanidade e o lugar do jornal; Redes urbanas e redes digitais: considerações sobre a governança eletrônica; Cidades, 
modernidade e fotografia: Brassai; Um flanêur em Paris. Cidades e Música Popular - Cidades e música: sensibilidades culturais urbanas; A cidade grande no imaginário do forró pé de serra atual; Som de preto, de proibição e tchutchucas: o Rio de Janeiro nas pistas do funk carioca.

\section{RIBAS, Júlio C. Planejamento por cenários prospectivos na educação a distância. São Paulo: Paco Editorial, 2014.}

O livro aborda o planejamento educacional, especificamente para a educação a distância, uma nova perspectiva de refletir, antever e projetar o futuro de forma clara, simples e consistente por meio da aplicação de um método. Analisa a importância desse método para construção e análise de cenários prospectivos, no âmbito da educação a distância e demonstra como esse planejamento contribui para a geração de uma estratégia efetiva, extrapolando as tendências e considerando os aspectos do futuro e as incertezas. Capítulos: Cenários prospectivos na educação a distância; O método para construção e análise de cenários prospectivos na EAD; Apresentação e análise dos resultados dos dados.

ROTHBLATT, Martine. Virtualmente humanos: as promessas e os perigos da imortalidade digital. São Paulo: Cultrix, 2016.

O livro aborda a simulação integral do cérebro humano por meio de softwares e tecnologias ligadas à informática e à Inteligência Artificial. Mostra com os seres humanos se depararão nas próximas décadas, à medida que a relação com o nosso eu digital evolui e se aprofunda, e oferece instrumentos filosóficos e tecnológicos para compreender as implicações de longo alcance do avanço da Inteligência Artificial. Capítulos: Um clone no mundo; O mim na máquina; Nosso Doppelgängers já existem; Clonagem mental, seleção natural e eugenia digital; Perdão pelas dificuldades técnicas que ainda tenho; Margem de manobra; Evolução ou revolução?; Repensar os Sistemas de Parentesco; Direito e liberdade; Deus e os clones mentais; O futuro do para sempre.

SANCHES, Marcia M. A sala de aula em filmes: lapidando a formação docente. São Paulo: Paco Editorial, 2014.

O livro apresenta sete produções fílmicas baseadas na realidade de diferentes épocas, fazendo uma análise em relação à atuação de educadores na sala de aula, e se na ação pedagógica dos protagonistas há um ensino educativo que contribua para a ampliação do processo de ensinar e de aprender. Discute a importância dos filmes na construção de novos saberes no ato educativo. Capítulos: A visão que desperta; Caminhos que se cruzam; A tessitura dos filmes e os complexos imaginários.

SANTOS, Roberto E.; ROSSETTI, Regina (orgs). Humor e riso na cultura midiática: variações e permanências. São Paulo: Paulinas, 2012.

O livro aborda a compreensão das maneiras como o humor é empregado nos produtos culturais midiáticos. Apresenta estudos sobre este fenômeno nos meios impressos e audiovisuais, na publicidade, no rádio e na música popular. Trata do humor e do riso na cultura midiática e contempla vários campos da comunicação: jornalismo, publicidade, televisão, cinema rádio, além de falar do humor na caricatura, na charge, na história em quadrinhos, na crônica, na imagem, nos sitcoms, no cinema e na música popular brasileira. Capítulos: Reflexões teóricas sobre o humor e o riso na arte e nas mídias massivas; O riso e a crônica jornalista; 
Riso cotidiano: as estratégias de humor nas tiras cômicas norte-americanas; Realismo e não realismo na construção do humor visual na publicidade; Humor na publicidade televisiva: entre o prazer e o mercado; Sitcoms: das relações com o tom; o humor na pornochanchada em dois tempos; Ligue o rádio: garantia de boas gargalhadas!; Música e humor na canção popular brasileira.

TAKAKI, Nara H. Letramentos na sociedade digital: navegar é e não é preciso. São Paulo: Paco Editorial, 2012.

O livro apresenta estudo sobre as novas formas de interação e navegação dos jovens na internet. Aborda as formas de interpretação e de construção de conhecimento no suporte digital, valorizando a criação e as autorias de aprendizes, preocupando-se com a relação academia e sociedade. Capítulos: Os novos letramentos e o hiperleitor, Sobre os 'novos letramentos, A hermenêutica crítica e suas relações com o letramento crítico, questão da crítica nas teorias de letramentos, A interpretação na linguagem digital: a construção de sentidos dos hiperleitores, O letramento crítico e a linguagem visual na interação dos hiperleitores.

ZACCHI, Vanderlei J.; WIELEWICKI, Vera H. Letramento e mídias: música, televisão e jogos digitais no ensino de Língua e Literatura. Maceió: Edufal, 2015.

O livro aborda as relações entre letramentos e diferentes mídias no ensino de língua e literatura, em especial da Língua Inglesa. Discute o ensino da Literatura a partir de textos presentes em outras mídias e formatos que não o livro impresso, como cinema, música, TV e teatro. Discute o ensino de língua e a formação de professores, a partir do trabalho com jogos digitais. Examina os diferentes textos e mídias, em suas especificidades e inter-relações, como potencialidade de letramento e construção de sentidos, o que pressupõe a capacidade de leitores e aprendizes de lidar com toda a diversidade de gêneros e formatos. Capítulos: Primeira Parte - Música, Televisão, Poesia e Letramentos - Entre Leonardo e Bethoven: reflexões sobre letramento, mídias e o leitor contemporâneo; Letramento multimodal via tradução e ensino de Literatura na terceira idade; Letramento multimodais e a poesia digital; Para além do Yeah! Rock ' $n$ "Roll e uma possibilidade de multiletramento no ensino de língua inglesa no Brasil. Segunda Parte - Jogos Digitais e Letramentos - A cultura lúdica e a cultura digital: interfaces possíveis; Explorando sentidos e aprendizados dentro de uma cultura de videogames; Interatividade e realismo no Pro Evolution Soccer; O cosmopolitismo pop de jogos digitais e a formação de professores de língua inglesa.

Luís Paulo Leopoldo Mercado

É Doutor em Educação (PUC/SP, 1998). Professor Associado IV vinculado ao Programa de Pós-Graduação em Educação da Universidade Federal de Alagoas. Avaliador ad-hoc da SEED/MEC, Sesu/MEC (Reuni), CAPES, CNPq, FINEP, FAPEAL. Avaliador Institucional do INEP. Possui publicações nacionais e internacionais na área de Educação a Distância, Tutoria Online e TIC na Educação. Lider do Grupo de Pesquisa Tecnologias da Informação e Comunicação na Formação de Professores Presencial e Online, certificado pelo CNPq. Coordenador Institucional de Educação a Distância da Universidade Federal de Alagoas. Coordenador da Universidade Aberta do Brasil na Universidade Federal de Alagoas. 